\title{
Production and purification of extracellular fungal cellulases using agricultural waste
}

\author{
Abishna Burugu, Dheerendra Kumar Suman, Chandrasekhar Chanda* \\ Department of Biotechnology, Koneru Lakshmaiah Education Foundation, Vaddeswaram, Guntur, Andhra Pradesh, India.
}

ARTICLE INFO

Article history:

Received on: October 27, 2020

Accepted on: December 20, 2020

Available online: March 10, 2021

\section{Key words:}

Cellulases,

Cost-effective production,

Rice husk powder,

Media optimization,

Submerged fermentation.

\section{ABSTRACT}

Cellulases are group extremely important enzymes which plays a crucial role in global carbon cycle by degrading insoluble cellulosic material. Cellulases can be used industrially in the economical and eco-friendly production of fermentation products. However, high cost of cellulases acting as a barrier for industrial scale usage of these enzymes. Cost-effective production of cellulases can be achieved by optimizing the media conditions and by choosing cheaper alternative lignocellulosic material as primary carbon and energy sources. In this study, we focused on production and purification of extracellular fungal cellulases using rice husk powder as primary carbon source in submerged fermentation. We performed optimization studies on cellulase production by varying inoculum size, initial substrate concentration, $\mathrm{pH}$ and supplementary carbon source. We observed a linear increase in cellulase production by increasing the inoculum size, initial substrate concentration and supplementary carbon concentration from $1 \%$ to $10 \%$. However, increase in initial substrate i.e., rice husk powder concentration above $10 \%$ we observed decrease in cellulase production probably due to the inhibitory effect of high initial substrate concentrations. We were able to optimize the fungal cellulase production up to a concentration of $134 \mathrm{IU} / \mathrm{ml}$ of broth using submerged fermentation

\section{INTRODUCTION}

Lignocellulose a major constituent of plant cell wall which is one of the most widely available renewable non-fossil carbon sources on earth. It is abundantly present in agricultural waste, fruit and vegetables waste, forest waste, and municipal waste [1-4]. Economical and eco-friendly production of bioethanol and other bioproducts can be achieved by utilizing cheaper lignocellulosic material as primary carbon and other energy sources [5-8]. However, high cost of cellulases is the major barriers preventing the usage of lignocellulosic material for industrial scale production [9-11]. Cellulases are the enzymes which can digest the insoluble cellulose polymer $[12,13]$. There are three major types of cellulases available in nature (1) Exoglucanases act on both reducing and non-reducing ends of the cellulose polymer and breaks non-covalent bonds in the amorphous structure, (2) Endoglucanases (cellobiohydrolase) act randomly on internal chain of cellulose and cleaves glucose units, and (3) $\beta$ glucosidase (cellobiose): Hydrolyses the $\beta$ 1-4 linkage in cellulose polymer $[14,15]$. Cellulose is obtained after hydrolysis of the lignocellulosic material. Cellulose as a substrate can trigger a wide variety of microorganism in producing extracellular cellulases into the fermentation media [16,17]. Optimal and costeffective production of enzymes can be achieved by culturing suitable

*Corresponding Author:

Chandrasekhar Chanda, Department of Biotechnology, Koneru Lakshmaiah

Education Foundation, Vaddeswaram, Guntur - 522 502,

Andhra Pradesh, India.

E-mail: chandrasekharchanda02@gmail.com organism in growth conditions [18-21]. Screening for the microorganism which produces cellulases and large-scale cost-effective production of cellulases has been a major area of focus for many researchers. In this article, we are focusing on the cost-effective production, optimization, and purification of extracellular fungal cellulases using rice husk powder as a primary carbon and energy source.

\section{MATERIALS AND METHODS}

\subsection{Media and Growth Conditions}

Fungal strain Penicillium funiculosum was obtained from the National Chemical Laboratory, Pune. Potato dextrose broth (basal media) was used to grow $P$. funiculosum at $30^{\circ} \mathrm{C}$ for $96 \mathrm{~h}$.

Mycelium was then transferred on to Reese and Mandel medium comprising (in g/L) peptone 2.5, yeast extract 2.0, $\left(\mathrm{NH}_{4}\right)_{2} \mathrm{SO}_{4} 1.5, \mathrm{CaCl}_{2}$ $0.3, \mathrm{KH}_{2} \mathrm{PO}_{4} 3, \mathrm{MgSO}_{4} 0.3$, urea $0.3, \mathrm{FeSO}_{4} \cdot 7 \mathrm{H}_{2} \mathrm{O} 0.005, \mathrm{MnSO}_{4} \cdot \mathrm{H}_{2} \mathrm{O}$ $0.0016, \mathrm{ZnSO}_{4} \cdot 7 \mathrm{H}_{2} \mathrm{O} 0.0014$, and $\mathrm{CoCl}_{2} 0.0012$, pH 5.0 supplemented with $1 \%$ glucose. Culture grown in basal medium for $96 \mathrm{~h}$ was then collected and centrifuged at 10,000 rpm for $20 \mathrm{~min}$. Culture was then washed and suspended in $100 \mathrm{ml}$ of $10 \mathrm{mM}$ phosphate buffer, $\mathrm{pH} 4.8$. Five percent mycelial suspension was used to inoculate fermentation media [22].

\subsection{Enzyme Production by Submerged Fermentation}

Rice husk was collected from agricultural fields and powdered after proper drying. Fermentation media was prepared by adding rice husk 
powder $(5 \% \mathrm{w} / \mathrm{v})$ and yeast extract $(0.1 \% \mathrm{w} / \mathrm{v})$, dextrose (initial substrate) (1-10\% range) in appropriate proportions and autoclaved at $121^{\circ} \mathrm{C}$ and $15 \mathrm{psi}$ for $20 \mathrm{~min}$. Inoculum size of $5 \%(\mathrm{v} / \mathrm{v})$ obtained from basal media was inoculated into fermentation media. Submerged fermentation was carried out in 5 liter flask and incubated at room temperature for 7 days. Once growth was observed biomass was collected and subjected to centrifugation at $10,000 \mathrm{rpm}$ for $10 \mathrm{~min}$ for the separation of mycelium.

\subsection{Cellulase Purification}

Supernatant collected after centrifugation was subjected to ammonium sulfate $(70 \%)$ precipitation. After precipitating the total proteins, the mixture was then subjected to centrifugation at $6000 \mathrm{rpm}$ for $5 \mathrm{~min}$. Protein pellet obtained was dissolved in $10 \mathrm{mM}$ phosphate buffer and subjected to dialysis against $10 \mathrm{mM}$ phosphate buffer several times to remove ammonium sulfate present in the sample. The crude sample was then collected into a fresh microcentrifuge tube and expected to have cellulases in it.

\subsection{Anion Exchange Column Chromatography}

Crude sample thus obtained was subject to anion exchange chromatography using diethylaminoethyl (DEAE) Sepharose fast flow column. The column was then packed with the sepharose matrix and equilibrated with $10 \mathrm{mM}$ phosphate buffer. Crude sample was then loaded on the matrix and immediately started collecting the flow through fractions of two bed volumes. Elution of bound proteins was done using three bed volumes of $\mathrm{NaCl}$ solution and by maintaining a gradient from 0 to $0.5 \mathrm{M}$ of $\mathrm{NaCl}$. Fraction size was limited to $1 \mathrm{ml}$ both in flow through and $\mathrm{NaCl}$ gradient. Absorbance was measured for all the eluted fractions at $280 \mathrm{~nm}$ and protein concentration was estimated using Bradford method. Chromatogram was plotted using absorbance values on Y-axis and fraction number on $\mathrm{X}$-axis for the above fractionation [Figure 1].

\subsection{Enzyme Activity Assay}

Filter paper cellulase activity (FPase) assay was performed using filter paper strip (Whatman no.1) of length $1 \times 6 \mathrm{~cm}$. Paper strip was incubated at $50^{\circ} \mathrm{C}$ for $1 \mathrm{~h}$ with $100 \mu \mathrm{l}$ of purified cellulase enzyme and $1 \mathrm{ml}$ of $20 \mathrm{mM}$ phosphate buffer. The solution was then boiled at $100^{\circ} \mathrm{C}$ for 20 min with vigorous shaking. $1.5 \mathrm{~mL}$ of 3,5-Dinitrosalicylic acid reagent was added to the solution and then filtered through a glass filter paper. Filtrate absorbance was measured at $540 \mathrm{~nm}$. Cellulases can reduce polysaccharide cellulose in filter paper to its subsequent sugar glucose. Enzyme activity was estimated in terms of concentration of glucose released during the reaction. To estimate the glucose concentration released during the reaction a standard graph was plotted using $0-1000 \mu \mathrm{g}$ dextrose. One hundred microliters of the purified cellulase enzyme were taken in test sample. One unit of cellulase activity was defined as the amount of enzyme that liberates $1 \mathrm{~mm}$ of reducing sugars equivalent to glucose per minute under the assay conditions described.

\section{RESULTS AND DISCUSSION}

\subsection{Production of Cellulases Using Submerged Fermentation}

P. funiculosum inoculum size ranging from 1 to $10 \%$ was used to optimize the production of extracellular fungal cellulases using submerged fermentation. Similarly, temperature and $\mathrm{pH}$ optimizations of the fermentation media were also done to improve the yield of extracellular fungal cellulase production. Submerged fermentation with rice husk (1-10\% concentration) as substrate was carried out in 51 flask for 7 days. Cellulases released into the broth were separated

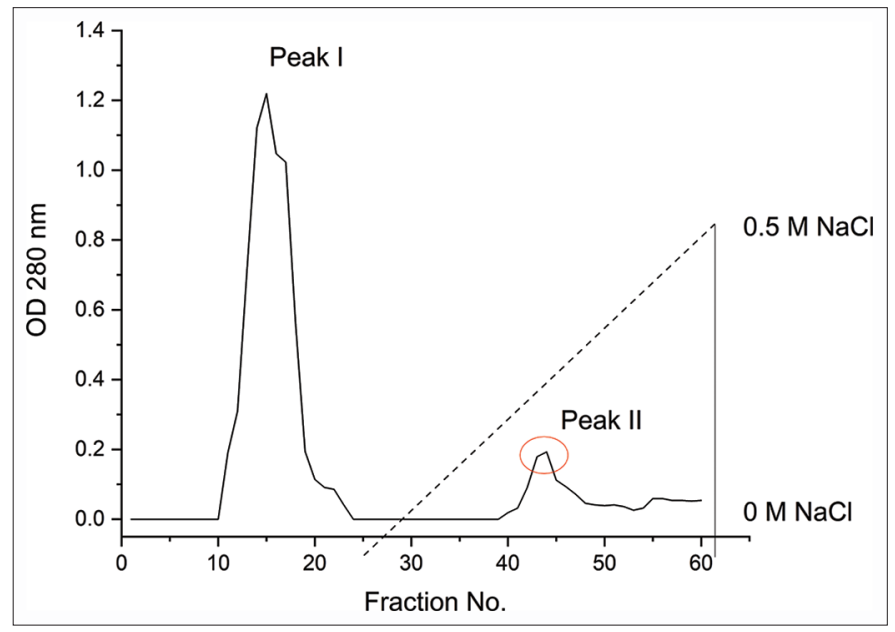

Figure 1: Purification of cellulase enzyme using DEAE Sepharose column chromatography. Above chromatogram representing two major protein peaks Peak I and Peak II. Peak II highlighted in the chromatogram got eluted at 0.3 $\mathrm{M} \mathrm{NaCl}$ gradient and showed adequate cellulase activity.

from the media constituents by centrifuging the broth at $10,000 \mathrm{rpm}$. Crude cellulases present in the supernatant sample were concentrated using ammonium sulfate precipitation.

\subsection{Purification of Cellulase Using Ion Exchange Chromatography}

Further purification of cellulases was done by fractionating the crude sample on anion exchange column chromatography using DEAE Sepharose matrix. Two major peaks were observed in the chromatogram Peak I eluted in the flow through and Peak II eluted at $0.3 \mathrm{M} \mathrm{NaCl}$ gradient, Figure 1. Both the peaks were tested for FPase activity assay whereas only Peak 2 showed very good cellulolytic activity. Amount of glucose released by cellulolytic activity on filter paper strip was calculated using the glucose standard graph and subsequently converted to enzyme activity units, Figure 2.

\subsection{Optimization of Cellulase Production}

\subsubsection{Effect of inoculum size on cellulase production}

With increase in inoculum size from 1 to $10 \%$, there was a linear increase in the enzyme production as observed from total cellulolytic activity assay, Figure 3.

\subsubsection{Effect of initial substrate concentration on cellulase production}

By increasing the initial concentrations of the substrate (i.e., rice husk powder) from 1 to $10 \%$, we observed a linear increase in the production of extracellular cellulases by $P$. funiculosum. However, with very high initial substrate concentration (i.e., 20\%), lower production of cellulases was observed when compared to $10 \%$ substate concentration at similar fermentation times. This is probably due to the repressive effects caused by high initial substrate concentration on cellulase production, Figure 4.

\subsubsection{Effect of supplement carbon on cellulase production}

Supplementing the fermentation media with simple carbon source, that is, glucose was found to be very effective in increasing the cellulase production. Using glucose concentration in the range $1-5 \%$, we observed a drastic increase in cellulase production when compared to cellulase production without supplementary carbon source, Figure 5. 


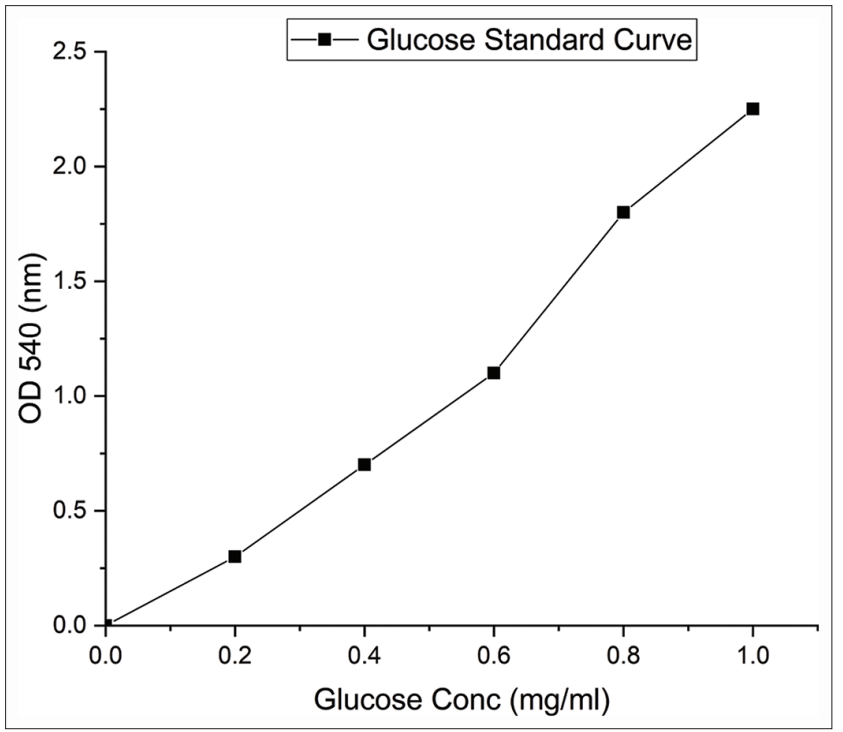

Figure 2: Glucose Standard curve is used for finding the concentrations of unknown sample i.e., Glucose released due to cellulase activity of the enzyme.

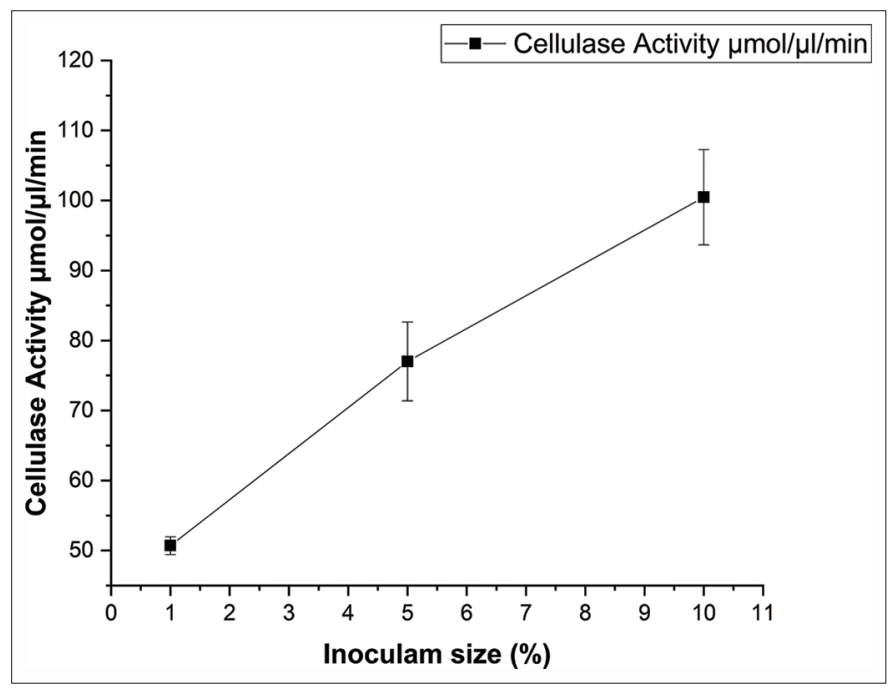

Figure 3: Effect of inoculum size on cellulase production during submerged fermentation.

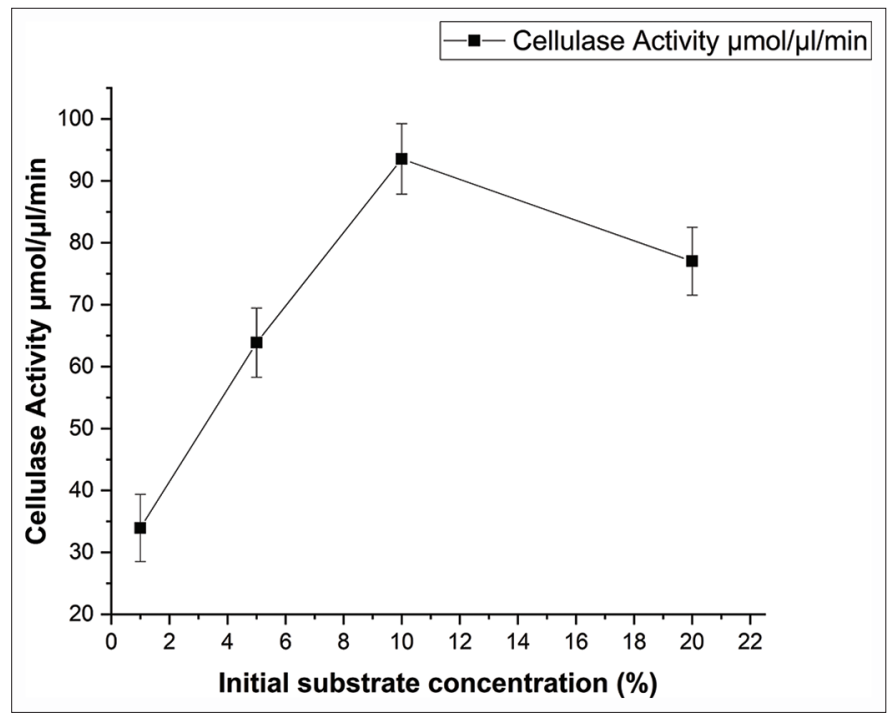

Figure 4: Effect of initial substrate concentration (i.e., rice husk powder) on cellulase production during submerged fermentation.

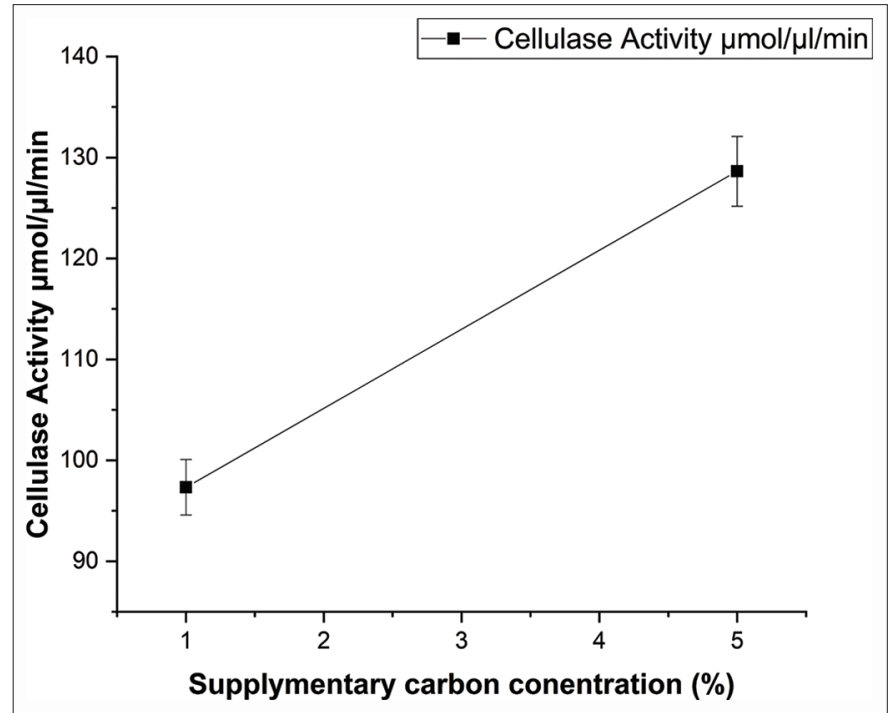

Figure 5: Effect of Supplementary carbon source (i.e., glucose) on cellulase production during submerged fermentation.

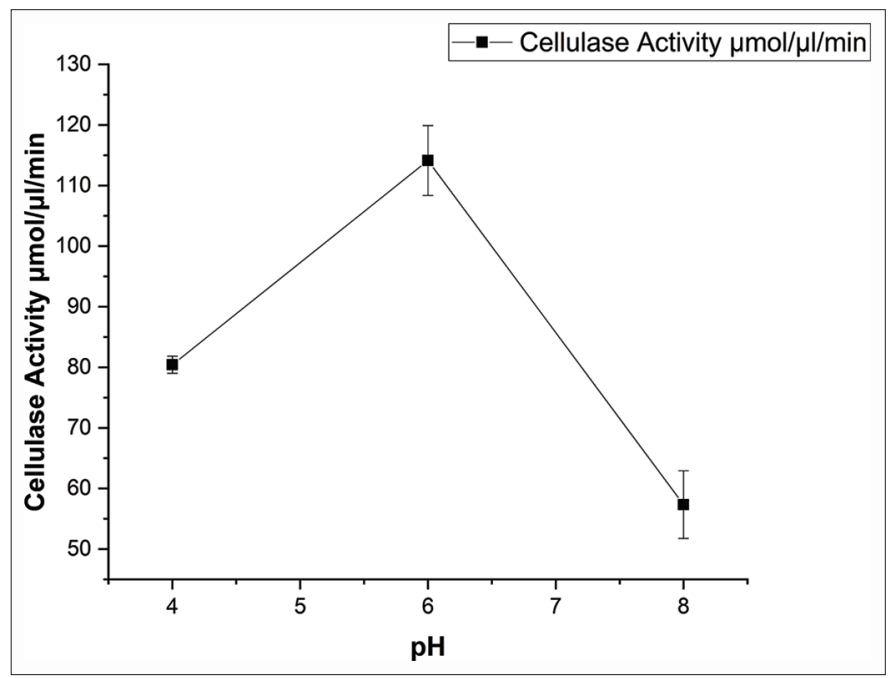

Figure 6: Effect of $\mathrm{pH}$ on cellulase production during submerged fermentation.

\subsubsection{Effect of $\mathrm{pH}$ on cellulase production}

By maintaining a $\mathrm{pH}-6$ during submerged fermentation yielded optimal productivity of cellulases, Figure 6 .

\section{CONCLUSION}

Saccharification of the carbohydrates obtained from cheaper alternative carbon sources like lignocellulose can be a major hurdle for the costeffective production of products by many food and pharma industries. Screening for the organism which produce cellulases, optimizing the media and growth conditions can leads to cost effective production of cellulases. In the current study, we focused on production and purification of extracellular fungal cellulase enzymes using agricultural waste material, that is, rice husk powder. By varying inoculum size, initial substrate concentration, $\mathrm{pH}$, and supplementary carbon source, we performed optimization studies on cellulase production. A linear increase in cellulase production was observed by increasing the inoculum size, initial substrate concentration, and supplementary carbon concentration from $1 \%$ to $10 \%$. We found $10 \%$ rice husk powder as primary carbon source and 5\% supplementary carbon 
source, that is, glucose was necessary to achieve optimal production of fungal cellulases using submerged fermentation. We were able to optimize the fungal cellulase production up to a concentration of $134 \mathrm{IU} / \mathrm{ml}$ of fermentation broth.

\section{ACKNOWLEDGMENT}

The authors would like to thank management Koneru Lakshmaiah Education Foundation Vaddeswaram, Guntur, for helping us with necessary resources.

\section{CONFLICTS OF INTEREST}

Authors declared that they do not have any conflicts of interest.

\section{REFERENCES}

1. Tomme P, Warren RA, Gilkes NR. Cellulose hydrolysis by Bacteria and fungi. Adv Microb Physiol 1995;37:1-81.

2. Zhang YH, Lynd LR. Toward an aggregated understanding of enzymatic hydrolysis of cellulose: Noncomplexed cellulase systems. Biotechnol Bioeng 2004;88:797-824.

3. Reddy GS, Pranavi S, Srimoukthika B, Reddy VV. Isolation and characterization of bacteria from compost for municipal solid waste from Guntur and Vijayawada. J Pharm Sci Res 2017;9:1490-7.

4. Sethupathy A, Arun C, Teja GR, Sivashanmugam P. Enhancing hydrogen production through anaerobic co-digestion of fruit waste with biosolids. J Environ Sci Health Part A Toxic Hazardous Subst Environ Eng 2019;54:553-9.

5. Sarkar N, Ghosh SK, Bannerjee S, Aikat K. Bioethanol production from agricultural wastes: An overview. Renewable Energy 2012;17:19-27.

6. Kang Q, Appels L, Tan T, Dewil R. Bioethanol from lignocellulosic biomass: Current findings determine research priorities. Sci World J 2014;2014:298153.

7. Kokkiligadda S, Srinivasa RR. Concentration and partial purification of essential fatty acids as co-products of biofuels from microalgal consortium. Res J Biotechnol 2017;12:25-34.

8. Anbessa TT, Karthikeyan S. Optimization and mathematical modeling of biodiesel production using homogenous catalyst from waste cooking oil. Int J Eng Adv Technol 2019;9:1733-9.

9. Liu G, Zhang J, Bao J. Cost evaluation of cellulase enzyme for industrial-scale cellulosic ethanol production based on rigorous Aspen Plus modeling. Bioproc Biosyst Eng 2016;39:133-40.

10. Klein-Marcuschamer D, Oleskowicz-Popiel P, Simmons BA, Blanch HW. The challenge of enzyme cost in the production of lignocellulosic biofuels. Biotechnol Bioeng 2012;109:1083-7.

11. Kante RK, Somavarapu S, Vemula S, Kethineni C, Mallu MR, Ronda SR. Production of recombinant human asparaginase from Escherichia coli under optimized fermentation conditions: Effect of physicochemical properties on enzyme activity. Biotechnol Bioproc Eng 2019;24:824-32.

12. Blanchette C, Lacayo CI, Fischer NO, Hwang M, Thelen MP. Enhanced cellulose degradation using cellulase-nanosphere complexes. PLoS One 2012;7:e42116.

13. Guder DG, Krishna MS. Isolation and characterization of potential cellulose degrading Bacteria from sheep rumen. J Pure Appl Microbiol 2019;13:1831-9.

14. Singhania RR. Production of celluloytic enzymes for the hydrolysis of lignocellulosic. In: Ashok P, Christian L, Steven CR, Claude-Gilles D, Edgard G, editors. Biofuels Alternative Feed-Stocks and Conversion Processes. Cambridge: Academic Press; 2011. p. 177-201.

15. Tanimura A, Liu W, Yamada K, Kishida T, Toyohara H. Animal cellulases with a focus on aquatic invertebrates. Fish Sci 2013;79:1-13.

16. Bahkali AH. Influence of various carbohydrates on xylanase production in Verticillium tricorpus. Bioresour Technol 1996;57:265-8.

17. Magnelli P, Forchiassin F. Regulation of the cellulase complex production by Saccobolus saccoboloides: Induction and repression by carbohydrates. Mycologia 1999;91:359-64.

18. Managamuri U, Vijayalakshmi M, Poda S, Ganduri VS, Rajulapati SB. Optimization of operating conditions for the production of enhanced antifungal metabolites from Streptomonospora arabica VSM 25 by full factorial design. J Young Pharm 2017;9:399-409.

19. Kante RK, Vemula S, Somavarapu S, Mallu MR, Boje Gowd BH, Ronda SR. Optimized upstream and downstream process conditions for the improved production of recombinant human asparaginase (rhASP) from Escherichia coli and its characterization. Biologicals 2018;56:45-53.

20. Kethineni C, Choragudi SF, Kokkiligadda S, Jaswanthi N, Ronda SR. Development of sequential processes for multiple product recovery from microalgae. Ind Biotechnol 2018;14:95-106.

21. Somavarapu S, Vemula S, Reddy IB. Extraction, purification and characterization of a novel cysteine protease from the latex of plant Vallaris solanacea. J Plant Biochem Biotechnol 2018;27:186-98.

22. Burugu A, Addanki M, Surepalli S, Chanda C. Optimization of xylanase production from penicillium funiculosum using agricultural (Corn cob) waste. Res J Pharm Technol 2020;13:4111-4.

\footnotetext{
How to cite this article:

Burugu A, Suman DK, Chanda C. Production and purification of

extracellular fungal cellulases using agricultural waste. J App Biol Biotech. 2021;9(2):153-156. DOI: 10.7324/JABB.2021.9214
} 